\title{
A comunicação de valores éticos na interação entre público e organizações: um estudo das postagens da Vale sobre 0 caso de Brumadinho
}

\author{
Luis Mauro Sa Martino ${ }^{1}$ \\ Fernanda Ravelli²
}

\begin{abstract}
Resumo
Este texto delineia algumas relações entre ética, comunicação e crise organizacional a partir do estudo de vinte postagens e interações da empresa Vale na rede LinkedIn referentes ao rompimento da barragem de Brumadinho-MG, em 2019, publicadas entre janeiro e julho desse ano. A análise indica que os valores comunicados se modificam de acordo com a cronologia dos acontecimentos e as interações do público: (1) no momento do evento, ressaltam-se a preservação da vida, a apuração dos fatos e ações de resgate; (2) conforme mais informações circulam nas semanas seguintes, destaca-se o reconhecimento da responsabilidade; (3) dois meses depois, retoma-se a divulgação dos valores da empresa como fundamento para evitar acontecimentos semelhantes. Esses resultados são discutidos a partir das pesquisas sobre ética e comunicação organizacional.
\end{abstract}

Palavras-chave

Ética. Comunicação Organizacional. Interações. Mídias Digitais.

\begin{abstract}
This text outlines some relations between ethics, communication and organization crisis by studying Vale Company's 20 posts - and its XXX comments - on LinkedIn regarding the tragedy of Brumadinho-MG, published between January and July 2019. Main findings suggests that the reported values change according to the chronology of the events and the interactions of the public: (1) at the moment of the event, the preservation of life, the verification of facts and rescue actions are emphasized; (2) in the following weeks, a greater deal of information concerning the company leads to the acknowledgment of responsibility; (3) Two months later, the communication of company values is resumed as a way to avoid future events. These results are grounded on ethics and organizational communication studies.
\end{abstract}

\section{Keywords}

Ethics. Organizational Communication. Interactions. Digital media.

1 Doutor em Ciências Sociais pela PUC-SP. Imsamartino@gmail.com

2 Mestranda em Comunicação pela Faculdade Cásper Líbero. nanda4p@gmail.com 


\section{VOZES $_{\text {\&IÁLORO }}^{\mid}$}

Itajaí, v. 18, n. 02, jul/dez 2019

\section{Introdução}

O estudo da ética na comunicação organizacional parece estar ganhando uma progressiva relevância nas pesquisas da Área. Além da presença do tema em eventos de repercussão nacional, como os congressos da Intercom e encontros da Compós, observase também uma produção científica constante, na forma de artigos, teses e dissertações que destacam essa intersecção. Vale acrescentar que a Organicom, uma das principais publicações acadêmicas dedicadas ao estudo da comunicação organizacional, já dedicou dois números ao tema, em 2008 (vol. 5, no. 8) e 2017 (vol. 14, no. 27). Se, de fato, o tema ainda não atingiu uma produção numérica comparável a dos estudos de ética no jornalismo, nota-se, no entanto, uma preocupação da Área em compreender melhor não apenas as questões de valor nas práticas comunicacionais, mas, sobretudo, a tripla intersecção entre ética, comunicação e organizações.

Broustau e Farmer (2014), na apresentação de um dossiê especial sobre ética e relações públicas da revista canadense Communiquer, indicam uma crescente demanda pela discussão do tema nas pesquisas dessa área, ao mesmo tempo em que muitos hiatos e lacunas ainda persistem nesse panorama, desafiando profissionais, pesquisadoras e pesquisadores à reflexão constante sobre o assunto.

Esses estudos parecem seguir, em boa medida, uma perspectiva normativa e deontológica em relação ao que pode ou não ser considerado "ético" na relação das organizações com seus públicos. Esses estudos, em sua maior parte, pautam-se em uma concepção filosófica de ética que nem sempre leva em consideração, ao lado da perspectiva das definições, códigos e normas, os imperativos da prática que regem, junto com outros fatores, a tomada de decisões no momento de divulgar uma determinada mensagem (RIVELLI; MARTINO, 2019).

Na observação de Johanna Fawkes (2012), o engajamento das pesquisas sobre ética nas relações públicas parece "curiosamente pouco reflexiva e sem engajamento com o pensamento corrente sobre ética profissional", e indica como isso deriva de posturas relativamente fixas no que diz respeito à relação profissional com questões éticas. Como aponta Barros Filho (1995) em seu estudo sobre o tema, essa área costuma levar em consideração condições ideias de produção e práticas comunicacionais, posicionando, às vezes, o tema da ética como um ideal ou um dever que, a rigor, pouco dialogaria com situações práticas.

Este artigo discute questões éticas e procedimentais da comunicação organizacional em momentos de crise, tomando como caso as postagens da empresa Vale referentes ao rompimento da barragem da empresa em Brumadinho - MG, dia 25 de janeiro de 2019. O fato deixou centenas de mortos e está entre dos maiores desastres ambientais relacionados ao rompimento de barragem de minério do mundo. 


\section{VOZES $_{\text {\&IÁLORO }}^{\mid}$}

Itajaí, v. 18, n. 02, jul/dez 2019

Nos meses subsequentes, a ampla repercussão do evento na mídia gerou uma série de respostas da empresa, dentre as quais uma série de postagens institucionais que formam efetivamente o corpus deste trabalho.

O tema não tem pretensões de ineditismo, sendo objeto de estudos específicos, por exemplo, de Reginato e Pozza (2013) sobre questões de ética e responsabilidade social da empresa Vale a partir de seus releases, enquanto Machado e Barichello (2015) estuda a comunicação online de crises corporativas. Em termos mais amplos, a questão da ética na comunicação organizacional vem sendo objeto da atenção, dentre outros, de trabalhos monográficos Andrade (2010), Paraventi (2013) ou Nascimento (2017), procurando compreender, sobretudo, aspectos da produção e veiculação das mensagens corporativas.

Não trataremos do fato em si, mas das articulações comunicacionais empregadas pela companhia no sentido de construir uma narrativa específica referente ao fato de maneira a reconstruir e/ou preservar sua imagem institucional. Busca-se extrair do fato referências para pensar a atitude da organização dentro de uma perspectiva ética e de valores - não no sentido propedêutico de uma deontologia, ou, menos ainda, da análise de códigos, mas, sobretudo, a partir das práticas de comunicação tal como podem ser vistas nas postagens.

O objetivo aqui não é enquadrar as postagens e a comunicação da companhia dentro de uma perspectiva ética já dada, seja qual for sua base; o caminho metodológico busca, ao contrário, observar quais são os valores da empresa presentes em sua comunicação - as postagens em redes sociais, no caso. Entende-se que a compreensão da ética organizacional tem uma dimensão prática, visível, dentre outros momentos, na comunicação que procura estabelecer com seu público.

Entende-se que a abordagem da ética nas organizações pode seguir um caminho pautado não apenas em um ponto de vista deontológico, mas também dos entrelaçamentos possíveis entre as questões cotidianas e os dilemas éticos que podem emergir a partir daí (RIVELLI; MARTINO, 2018, p. 5). No que se segue, o texto é dividido em três partes: (1) Situa-se brevemente a questão da ética como prática na comunicação organizacional para, em seguida (2) focalizar o momento inicial de formulação da comunicação dos valores sobre o caso de Brumadinho e (3) suas transformações decorrentes das interações com o público e as mudanças na organização.

\section{De que ética estamos falando?}

O tema da ética nas organizações parece ocupar um lugar paradoxal nos estudos de Comunicação. Uma revisão bibliográfica inicial realizada em outro momento (RIVELLI; MARTINO, 2018) sugere que, no Brasil, apesar da dimensão que o tema tem no discurso da área, a produção acadêmica ainda é esparsa e feita, sobretudo, a partir de uma matriz da ética filosófica, não propriamente de Comunicação. 


\section{VOZES $_{\text {\&IÁLOGO }}^{\mid}$}

Itajaí, v. 18, n. 02, jul/dez 2019

Além disso, observou-se certa dispersão teórica e metodológica nas abordagens do assunto, sugerindo que a própria produção do campo ainda busca encontrar espaços de circulação. Entende-se, por isso mesmo, que a ausência de consenso a respeito do que constitui, efetivamente, um referencial de análise e interpretação dos fenômenos na área de Comunicação, torna os estudos nesta área particularmente necessários e desafiadores. Um levantamento bibliográfico de Andrade (2009) já sugeria um cenário de troca entre estudos de comunicação e administração no que tange à ética nas organizações.

Nesse sentido, é talvez importante sublinhar que a perspectiva da ética das organizações, tal como se apresenta e pode ser observada na comunicação das empresas, se insere em um quadro mais amplo de referências, práticas e interesses - em particular, aqueles referentes, de um lado, à cultura organizacional e, de outro, a geração de lucro dentro de uma economia de mercado (SROUR, 2008). Dessa maneira, a ética não pode ser separada dos outros interesses que regem as práticas organizacionais.

A cultura da empresa pode variar, assim como a missão, a visão e os valores que norteiam a sua atuação e o modelo de gestão que será seguido para o alcance dos resultados, mas o foco no resultado financeiro é condição essencial para a continuidade de toda e qualquer empresa. Verhoeven et alli (2018, p. 474) indica esse paradoxo, assinalando que organizações "devem ser autênticas, porque o público critico demanda autenticidade, ao mesmo tempo em que devem ser estratégicas para atingir seus objetivos", e não deixam de afirmar que "precisam ser éticas e transparentes, mas também espera-se que consigam o maior lucro possível".

Ao mesmo tempo, essas demandas de lucro e resultado também, por sua vez, não existem de maneira autônoma, mas inserem-se, em uma articulação tensional, em um ambiente no qual outros valores em circulação na sociedade podem entrar em jogo. É, portanto, dentro de uma dinâmica de campo, no qual diversas variáveis estão inseridas, que se pode pensar a ética na comunicação organizacional.

A ética de uma organização não perde de vista a questão, em última instância, da geração de lucros; ao mesmo tempo, em uma perspectiva agonística, essa própria perspectiva está relacionada, em diferentes medidas, à imagem da organização perante seus públicos - ao que parece, não é possível reduzir um fator ao outro sem deixar de lado que a dinâmica da comunicação organizacional se pauta igualmente em um tensionamento entre valores diferentes, às vezes antagônicos, entre si. Peres-Neto (2013), por exemplo, indica alguns aspectos dessa questão no discurso sobre o "consumo consciente".

As diferentes pressões, vindas de instâncias diversas da sociedade, para que as empresas sejam também eticamente orientadas contribuiu para que a ética se tornasse um diferencial competitivo, conforme apontado por Dupas (2008), sendo mais um produto, que ao ser vendido, seja através do discurso, da publicidade e propaganda e da relação com os empregados, também atende ao objetivo principal de retorno financeiro. Como ressaltado em outro momento (MARQUES, 2011; MARTINO, 2013; MARTINO; 


\section{VOZES $_{\text {\&IÁLOGO }}^{\mid}$}

Itajaí, v. 18, n. 02, jul/dez 2019

MARQUES, 2018), a ética pode, em alguns momentos, ser também uma estratégia para a conquista de espaços de maior prestígio e reconhecimento dentro de um campo, algo assinalado, em outra perspectiva e resultado, também por Peres-Neto (2014).

Soma-se a essa questão dos interesses corporativos uma segunda dimensão, também a ser levada em conta. Mesmo que empresas contem com estrutura de governança corporativa, códigos de ética e de conduta, canais de denúncia e comitês de ética, é necessário levar em consideração o lugar do humano dentro dessa perspectiva, com suas potências e limites. Nesse sentido, se é possível um instante para o pensamento especulativo, é possível questionar, por exemplo, qual é o espaço da subjetividade na tomada de decisões vinculadas a questões éticas.

No âmbito organizacional - assim como, talvez em determinados aspectos do espaço pessoal - crises relacionadas a procedimentos não nascem necessariamente grandes, mas são gestadas a partir de pequenos desvios, aos quais às vezes não se dá importância, talvez por sua aparente banalidade ou por estarem inseridos em atividades rotineiras: um e-mail com informações relevantes que é ignorado, um prazo de vistoria não cumprido, uma recomendação deixada de lado, uma conversa ouvida nos corredores e que foi mantida em silêncio.

Essas questões e procedimentos são, em geral, restritas ao âmbito de visibilidade limitada das práticas internas de cada organização e, por isso mesmo, discutidos dentro desse espaço restrito. No entanto, em momentos de crise, esses procedimentos são convocados pela visibilidade pública que recebem, e passam a ser objeto de discussão. É nesse momento em que a comunicação organizacional se apresenta para gerenciar os limites dessa visibilidade e da circulação de narrativas sobre a empresa. Rosa e Chevitarese (2017) indicam elementos semelhantes no que diz respeito às demandas na comunicação organizacional relacionadas à visibilidade constante nas redes sociais.

Nesse instante, eventuais discrepâncias entre o discurso público da organização e seus procedimentos - ou seus resultados - tornam-se visíveis e são revestidos de um valor que, em última instância, se articula com outras variáveis responsáveis pelos resultados de mercado esperados.

É a partir da forma como a empresa se posiciona, a partir de sua identidade corporativa, de como ela se mostra, que ela será cobrada. No caso da Vale, objeto deste artigo, a exposição dos acontecimentos de Brumadinho parece ter criado fricções e atritos discursivos e valorativos com os quais a comunicação organizacional precisa lidar no sentido de cuidar de uma imagem pública.

Assim, a comunicação da organização é um espaço de visibilidade de suas perspectivas éticas e normativas, tanto quanto suas práticas, trabalhando em dimensões humana e estratégica (KUNSCH, 2012) da comunicação e, não somente ou prioritariamente, da sua dimensão instrumental. A presença acessória do departamento de comunicação em algumas organizações parece não levar em consideração que, no que Han 


\section{VOZES $_{\text {\&IÁLORO }}^{\mid}$}

Itajaí, v. 18, n. 02, jul/dez 2019

(2018) denomina uma "sociedade da transparência”, a visibilidade dos valores éticos parece estar direta e constantemente relacionada com as outras perspectivas valorativas da organização - em sentido similar, Peres-Neto (2014) reavalia a ideia de transparência e "accountability" em um contexto de normatividade ética.

\section{A formulação do discurso no momento do acontecimento}

A comunicação feita pela Vale sobre Brumadinho também passou pelo perfil que a empresa mantém em sites de redes sociais digitais como o Twitter, o Facebook e o LinkedIn. Cada site, com suas características próprias, faz parte da estratégia de comunicação da Vale para sua versão dos fatos, seu posicionamento diante do ocorrido e reforçar os valores éticos que compõem o discurso da empresa.

Neste artigo, nos limitaremos a analisar a comunicação da tragédia feita pela empresa no LinkedIn, destacando postagens e interações com o público. Este site, por seu caráter corporativo, é amplamente utilizado pelas empresas para construção de sua imagem pública e melhorar a sua reputação, entendida, com Argenti (2006, p. 96), como o "somatório de identidade e imagem", em um processo "construído ao longo do tempo, independentemente de percepções isoladas em um determinado período" - para uma discussão mais ampla do conceito, remete-se a Andrade (2012).

A Vale, até julho de 2019, contava com 1.106.692 seguidores no LinkedIn, superior ao de empresas como Bradesco (613.192 seguidores), Magazine Luiza (318.120 seguidores) e Rede Globo (503.501 seguidores), por exemplo, que figuram entre as marcas mais valiosas do Brasil ${ }^{3}$.

Considerando que a identidade corporativa da Vale, também especificada em sua Missão, Visão e Valores, está calcada em um discurso de ética (agir da forma correta) e de preservação da vida (a vida em primeiro lugar), nos pareceu relevante observar de que forma a comunicação destes valores foi feita (e se foi feita) com vistas à gestão de sua reputação em um momento de crise.

Nesse aspecto, se considerarmos essas postagens como parte de uma narrativa organizacional, elas podem se apresentar como um índice para a observação de seus valores. Em seu perfil no LinkedIn, antes da tragédia em Brumadinho, a Vale, reforçava a imagem de empresa inovadora e tecnológica, preocupada com questões humanas, ambientais e com o desenvolvimento sustentável. O rompimento da barragem apresentase também como uma transformação narrativa, na qual há uma mudança nos valores expostos - o alto desempenho corporativo é substituído pela construção de uma imagem de preocupação com o ocorrido.

3 Empresas mais valiosas segundo o ranking BrandZ Brasil realizado pela WPP e a Kantar. Disponpivel em: https://br.kantar.com/mídia/. Acesso em: 04 de julho de 2019. 


\section{VOZES $_{\text {\&IÁLORO }}^{\mid}$}

Itajaí, v. 18, n. 02, jul/dez 2019

Nesse sentido, vale voltar o olhar, ainda que de maneira breve, para a comunicação imediatamente anterior ao evento, no sentido de compreender a existência de uma ruptura narrativa relacionada ao evento.

Em termos metodológicos, Zamanis, Giaglis e Kasimati (2015) acompanham o desenvolvimento cronológico de uma situação de crise, mostrando as diferentes abordagens do assunto que se desenrolam ao longo do tempo. Em sentido semelhante, propomos um retrospecto das 10 últimas postagens da empresa até a ocorrência da tragédia em Brumadinho (quadro 01):

Quadro 01: 10 últimos post da empresa Vale antes do evento de Brumadinho

\begin{tabular}{|c|c|}
\hline Data & Tema \\
\hline jan/2019 & Inauguração de um Centro de Inteligência Artificial da Vale \\
\hline dez/2018 & Utilização de soluções mais eficientes e sustentáveis na mineração \\
\hline dez/2018 & $\begin{array}{l}\text { Vale como apoiadora da transformação social por meio de leis de } \\
\text { incentivo }\end{array}$ \\
\hline $\operatorname{dez} / 2018$ & $\begin{array}{l}\text { Artigo sobre a importância dada à preservação dos Direitos Humanos e } \\
\text { como a empresa atua na gestão do tema em seus negócios }\end{array}$ \\
\hline nov/2018 & $\begin{array}{l}\text { Celebração do Dia Mundial do Combate à Corrupção e reforço da } \\
\text { mensagem sobre o quanto a ética tem um valor inestimável para a } \\
\text { empresa }\end{array}$ \\
\hline nov/2018 & $\begin{array}{l}\text { Iniciativas que unem tecnologia e mineração para práticas mais } \\
\text { produtivas e seguras }\end{array}$ \\
\hline nov/2018 & $\begin{array}{l}\text { Publicação anual sobre pesquisa e desenvolvimento que reforça a } \\
\text { existência de mais de } 850 \text { mil hectares de área verde protegidas pela } \\
\text { empresa }\end{array}$ \\
\hline nov/2018 & Encontro anual com investidores, jornalistas e analistas \\
\hline nov/2018 & $\begin{array}{l}\text { Divulgação do ranking da Corporate Human Rights Benchmark (CHRB) } \\
\text { - que classifica as empresas com melhor desempenho em Direitos } \\
\text { Humanos - e que classificou a Vale como a única empresa brasileira } \\
\text { entre as dez mais bem avaliadas, ocupando o } 6^{\circ} \text { lugar na colocação }\end{array}$ \\
\hline out/2018 & Divulgação de resultados financeiros e de produção \\
\hline
\end{tabular}

A mudança vem dia 25 de janeiro de 2019, quando Vale anuncia em seu perfil no LinkedIn a ocorrência do rompimento de sua barragem na cidade de Brumadinho com um post específico (figura 01): 


\section{VOZES $_{\text {\&IÁLOGO }}^{\mid}$}

Itajaí, v. 18, n. 02, jul/dez 2019

Figura 01: reprodução do post da empresa de 25.01.2009

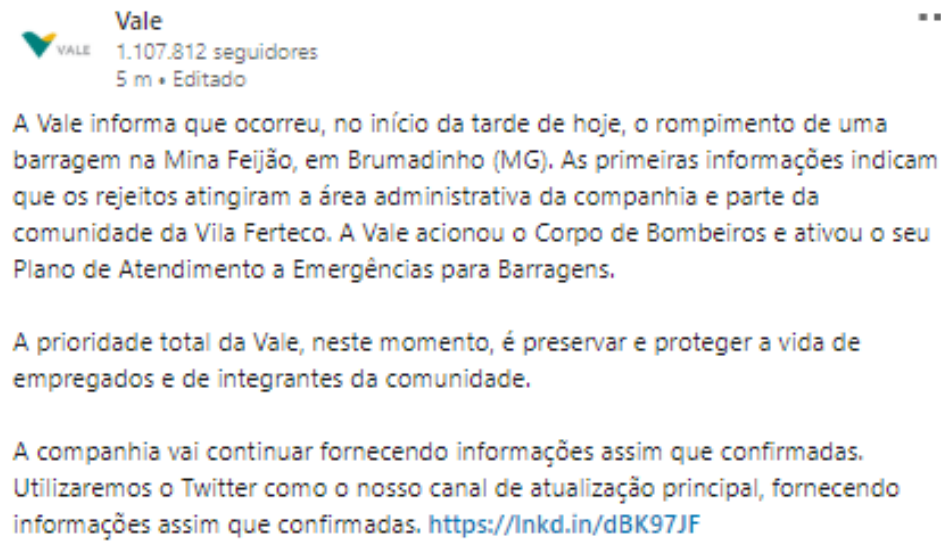

Fonte: https://www.linkedin.com/posts/vale_a-vale-informa-que-ocorreu-noin\%C3\%ADcio-da-activity-6494619446743826432-AJom

Se, até então, as postagens eram acompanhadas de imagens coloridas, com mensagens destacando as qualidades da empresa, visível, por exemplo, no uso de hashtags como \#orgulhodeservale e \#SomosRedescobridores, o primeiro post após o rompimento da barragem já apresenta outra identidade, em cores menos vivas, como cinza. A figura 02 ilustra essa mudança nas publicações:

Figura 02: comparativo da identidade visual dos posts antes e depois do evento

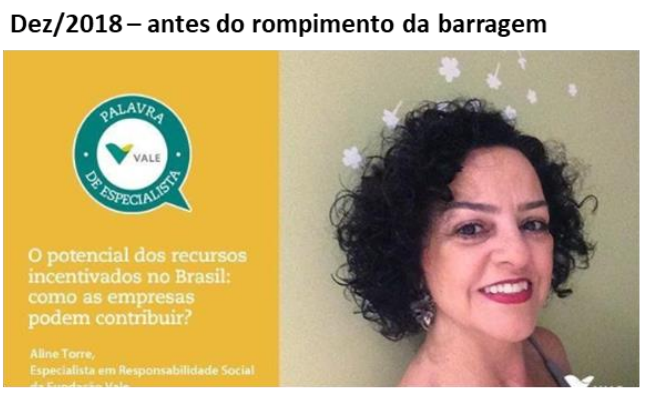

Abril/2019 - após rompimento da barragem

Elaborado pelo autor

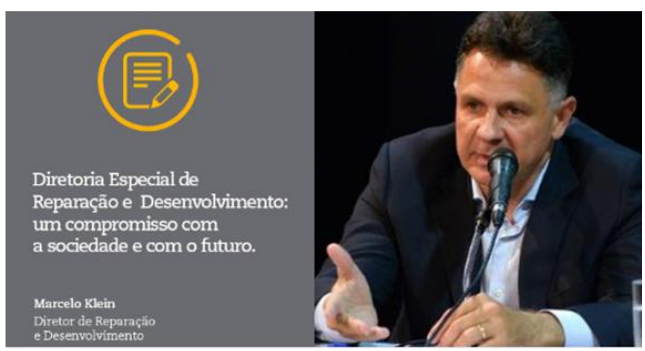

Fonte: elaborado pelos autores a partir de

https://www.linkedin.com/posts/vale_voc\%C3\%AA-sabe-como-uma-empresa-podecontribuir-activity-6484403016693796864-xBdL e

https://www.linkedin.com/posts/vale_diretoria-de-repara\%C3\%A7\%C3\%A3o-edesenvolvimento-activity-6529718721835991040-XrFR

Assim como a identidade visual das postagens foi revisada, nota-se uma mudança nos temas das publicações e no teor das respostas dadas pela empresa durante a comunicação com os usuários que enviam comentários. De 25 de janeiro até o final de julho de 2019, a Vale publicou vinte postagens no LinkedIn, todas fazendo referência ao 


\section{VOZES $_{\text {\&IÁLORO }}^{\mid}$}

Itajaí, v. 18, n. 02, jul/dez 2019

rompimento da barragem, alterando consideravelmente a dinâmica de temas da página. As vinte publicações podem ser classificadas em 6 categorias temáticas (quadro 02):

\section{Quadro 02: Caracterização das postagens da Vale no Linkedln após o evento}

\begin{tabular}{|c|c|}
\hline Categoria & Número de postagens \\
\hline Ações adotadas & 10 \\
\hline Comunicados & 3 \\
\hline Reestruturações internas & 3 \\
\hline Entrevistas coletivas & 2 \\
\hline Esclarecimentos & 1 \\
\hline Informações financeiras & 1 \\
\hline Total & 20 \\
\hline
\end{tabular}

Fonte: elaborado pelos autores

Conforme indica o gráfico, as postagens sobre as ações adotadas pela empresa para a minimização dos impactos do rompimento da barragem são a maioria, totalizando 10 dentre as 20 publicações.

\section{As interações com o público e as transformações na narrativa}

Em uma situação de crise corporativa, o comportamento dos atores nos sites de redes sociais é alterado. Novas demandas do público costumam imediatamente aparecer, sendo elaboradas e respondidas a partir de um conjunto de decisões tomadas no sentido não apenas de responder pontualmente a esses questionamentos e interpelações, mas, sobretudo, no sentido da construção de um discurso organizado e coerente, que ressalte os posicionamentos da empresa de maneira a buscar diminuir o impacto dos eventos. Como salientam Verhoeven et all (2018, p. 477), "uma das características da cultura hipermoderna é a existência de um público muito assertivo, que espera das organizações uma participação ativa nos debates da sociedade”.

É importante observar, no caso analisado neste artigo, que a narrativa organizacional parece ser diretamente elaborada a partir das interpelações do público, selecionando, no entanto, a representatividade dos comentários a serem respondidos.

As interações do público na página da Vale, caracterizado até o rompimento da barragem por mensagens expressando uma perspectiva de aprovação e entusiasmo pela empresa, reforçando o reconhecimento de suas conquistas, renome internacional, ações em prol do meio ambiente e valorização de seus funcionários, ganha novos contornos, questionando a ética da empresa, a congruência do discurso organizacional, e o principal valor comunicado pela empresa, “a vida em primeiro lugar". Destaca-se também a preocupação, nos comentários e interações, com a reincidência de casos de rompimentos de barragens, recordando a barragem que se rompeu na cidade de Mariana-MG, em 2015. 


\section{VOZES $_{\text {\&IÁLORO }}^{\mid}$}

Itajaí, v. 18, n. 02, jul/dez 2019

A partir dessa mudança na perspectiva do público, a empresa também passou por transformações na forma de agir e interagir com o usuário. Se, anteriormente, as respostas da organização eram agradecimentos aos comentários elogiosos, após o rompimento da barragem em Brumadinho a empresa passa a lidar com milhares de comentários críticos e questionadores. Trata-se, a rigor, de uma mudança no que Gouveia e Tavares (2014, p. 123) chamam de "imperativo da positividade" na comunicação das organizações no ambiente das mídias digitais.

Quando um ator, neste caso o usuário, expõe sua opinião, há uma expectativa sobre a reação do outro ator, ou seja, a Vale. A interação, como tipo ideal, implica sempre uma reciprocidade de satisfação entre os envolvidos e compreende também as intenções e atuações de cada um, conforme apontam Parsons e Shill (1975), mesmo que prevaleça entre eles, um laço fraco, "caracterizado por relações esparsas, que não traduzem proximidade e intimidade, mesmo um laço dialógico e uma interação mútua” (RECUERO, 2009, p. 41).

O primeiro post da Vale após o rompimento da barragem de Brumadinho, publicado no mesmo dia da tragédia, recebeu 853 comentários, dos quais a Vale respondeu a 44, cerca de 5\%. No dia da postagem, com poucas informações oficiais sobre as dimensões do ocorrido, o principal teor das respostas da Vale dizia respeito ao interesse da empresa na apuração dos fatos, reforçando seu compromisso com a transparência e sua atuação ética, conforma mostra uma das respostas, em 25 de janeiro de 2019:

\footnotetext{
A Vale é a maior interessada no esclarecimento das causas do rompimento da barragem e compartilhou espontaneamente informações apuradas até o momento com as autoridades policiais e com o Ministério Público. Reiteramos nosso compromisso de colaboração total e irrestrita dos empregados da Vale com as autoridades e faremos o possível para atenuar o sofrimento das vítimas e de seus familiares.
}

O segundo post da Vale foi a divulgação do comunicado do então presidente da empresa, Fabio Schvartsman, sobre a tragédia. Neste caso, o número de comentários recebidos foi consideravelmente maior que o da publicação anterior, totalizando 1.346, com a Vale respondendo a 41, 3\% do total. O tom principal das respostas, neste segundo post, caracterizava-se pelo lamento a respeito do ocorrido, como exemplificado neste comentário: "Carlos, lamentamos muito pelo o que aconteceu. Estamos mobilizando equipes para dar todo o suporte às pessoas atingidas e reparar os danos causados pelo ocorrido".

Quando o usuário respondia ao comentário da Vale, dando sequência ao diálogo, a empresa limitava-se a responder apenas ao comentário inicial, sem dar continuidade à conversa estabelecida - isso é observado, em outro contexto de crise, quando Zamanis, 


\section{VOZES: \\ ¿DIÁlOGO}

Itajaí, v. 18, n. 02, jul/dez 2019

Giaglis e Kasimati (2015) indicam que as transformações nos conceitos de reputação e imagem das organizações estão relacionadas às interações com públicos nas mídias digitais.

Uma postagem que se destacou pela repercussão positiva foi sobre a confirmação do nome do novo presidente da Vale, Eduardo Bartolomeu, em 29 de abril. Com esta publicação, a Vale recebeu 602 comentários, respondendo 225, 37\% deles. Este post, diferente dos demais, contou com considerável número de comentários positivos, que ressaltavam a trajetória profissional do novo presidente e a importância da atitude da empresa em trocar de presidente. Esse foi o único post em que o percentual de respostas da companhia ultrapassou $25 \%$ do número de comentários. O gráfico 01 pode auxiliar na observação dessas proporções:

Figura 02: Percentual de respostas da empresa aos comentários

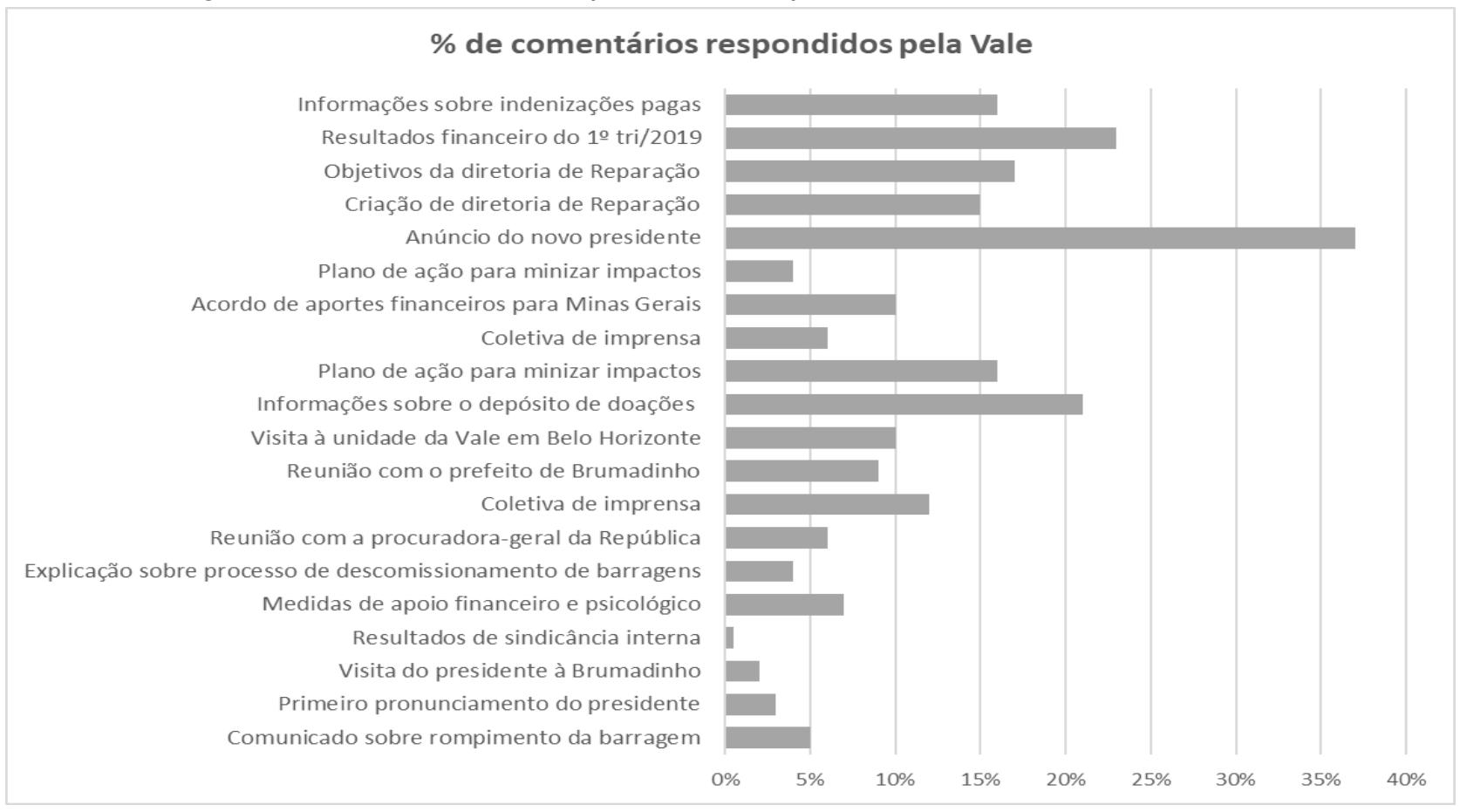

Fonte: elaborado pelos autores

À medida em que a tragédia em Brumadinho ganhava novos contornos, a Vale continuava a postar informações sobre as ações adotadas pela empresa para a minimização de impactos, elaborando as respostas a partir de eixos temáticos centrais que envolviam o ocorrido, com pequenos ajustes para se adequar, por exemplo, ao nome do usuário. Identifica-se aqui uma transição na forma de comunicar os valores éticos, passando do compromisso da empresa para sua afirmação prática a partir de mensagens que enfatizavam trechos como: "não vamos medir esforços", "sabemos da nossa responsabilidade", "vamos trabalhar juntos pela segurança”, entre outros, como podemos identificar abaixo, como neste post de maio de 2019: 


\title{
VOZES $_{\text {\&IÁLORO }}^{\mid}$
}

Itajaí, v. 18, n. 02, jul/dez 2019

\begin{abstract}
Sabemos que é de nossa responsabilidade reparar todos os danos causados à Brumadinho, Suellen. Ainda há muito a ser feito, e por isso, estamos dando total assistência às pessoas atingidas e cuidando também da recuperação ambiental da cidade. Confira todas as nossas ações pelo site: www.vale.com/brumadinho.
\end{abstract}

Há uma terceira mudança no teor das interações. Meses após o acontecimento, comentários do público começam a sugerir a necessidade de mudanças de maior porte na sociedade, apresentando uma visão mais ampla da tragédia. As respostas da empresa em seus posts, além de destacar as ações adotadas, retomam a apresentação de seus valores, mostrando o que a empresa tem feito para minimizar os danos, como na resposta a seguir, postada em junho de 2019:

Rosa, sabemos que ainda há muito a ser feito, mas estamos nos esforçando para recuperar a cidade e estamos prestando total assistência às pessoas atingidas. Além disso, sempre nos dedicamos para que todas as barragens recebam o cuidado que necessitam. Para isso, quinzenalmente, são realizados monitoramentos e inspeções em todas as estruturas que se enquadram na Política Nacional de Segurança de Barragens. Ao todo, são mais de 2000 inspeções por ano, reportadas e analisadas em um sistema integrado de gestão.

Neste terceiro momento da estratégia de comunicação da Vale no LinkedIn, a empresa também passa a enfatizar as ações para o descomissionamento de barragens, tentando redesenhar o rumo da conversa, em uma tentativa de tirar o foco do presente e enfatizar o que pode vir a ser diferente no futuro.

\section{Considerações finais}

Anne-Marie Gagné (2012), em sua tese de doutorado, mostra que o estabelecimento da confiança entre marcas e públicos nas relações públicas é um processo multifatorial, que requer uma atenção não apenas dos atores envolvidos, mas também das perspectivas de seus públicos.

As pesquisas sobre comunicação organizacional ocupam um lugar já consolidado na Área, acompanhando a importância crescente da preocupação com as formas de construção da visibilidade pública das organizações, como destaca Kunsch (2006). Nesse cenário, as pesquisas sobre ética, se ocupam ainda um espaço relativamente restrito, mostram uma tendência de crescimento na medida em que a comunicação de valores éticos se torna um dos principais aspectos da imagem, identidade e reputação de uma organização - e, por isso mesmo, participante dos interesses de mercado relacionados a sua existência. 


\section{VOZES $_{\text {\&IÁLORO }}^{\mid}$}

Itajaí, v. 18, n. 02, jul/dez 2019

Em geral, a ética, conceito polissêmico e aberto, permite diversas construções práticas e discursivas referentes ao que seria, de fato, uma atuação organizacional "ética". Ao mesmo tempo, há uma forte pressão de setores da sociedade, reverberando no âmbito das mídias digitais, no sentido de exigir das organizações posicionamentos, assim como para que tenham, efetivamente, ações eticamente responsáveis e orientadas.

No entanto, a presença da palavra nos quadros de missão e valores das organizações não significa necessariamente que se tenha uma perspectiva definida do que isso significa para além das concepções imediatas do comum. Daí a necessidade, abordada neste texto, de verificar qual é a ética dos posicionamentos adotada em uma determinada situação.

Devido às incongruências existentes entre a aplicação de ética pura com a lógica capitalista regida por práticas mercadológicas onde "somos todos pressionados a consumir mais, e, nesse percurso, nós mesmos nos tornamos produtos nos mercados de consumo e de trabalho" (BAUMAN, 2011, p. 65), um caminho possível para a construção empresas mais éticas seria àquele em que discurso e práticas seguem a mesma direção, inclusive na identificação das vulnerabilidades da empresa e os limites éticos da própria comunicação organizacional.

As empresas estão sujeitas a crises organizacionais, mas o impacto e a dimensão que a crise assume leva em conta a coerência entre o que é dito e o que é feito pela empresa, o que ela discursa e o que ela pratica. Nesse aspecto, Dutta-Bergman (2005) ressalta os desafios e dificuldades do trabalho de relações públicas perante as crescentes interpelações dos vários setores da sociedade civil.

No caso da Vale estudado neste texto, observou-se que a estratégia de comunicação de valores éticos passou por três etapas: na primeira delas, a empresa reforçava seu interesse pela apuração dos fatos, reforçando seu compromisso com a transparência e sua atuação ética; em segundo momento, já com o grande número de informações circulando na imprensa, a empresa passou a trabalhar com mensagens como "não vamos medir esforços", "sabemos da nossa responsabilidade" e "vamos trabalhar juntos pela segurança; finalmente, a empresa reconduziu a sua comunicação para mostrar o que estava sendo feito para minimizar os danos e evitar novos acontecimentos da mesma natureza.

A visibilidade decorrente do processo de midiatização, recorda Martino (2019), leva em conta que as práticas sociais - no caso, as atividades organizacionais - articulam-se com um ambiente midiático. Nesse processo, as empresas passam a lidar com pressões vindas de diversas frentes, olhares atentos de outros setores da sociedade, normas e regulamentos, e, consequentemente, com preocupações que vão além da entrega dos produtos e serviços prometidos, mas que perpassam também, a forma como são produzidos e entregues à sociedade. $\mathrm{O}$ máximo de transparência, correspondendo ao máximo de vigilância, não deixa de ser também uma variável para a comunicação, na qual a imagem da organização constitui-se enquanto valor. 


\section{VOZES \\ DIÁLOGO}

Itajaí, v. 18, n. 02, jul/dez 2019

\section{Referências}

ANDRADE, Zilda A. F. Ética organizacional e construção da reputação. Trabalho apresentado no XIII Intercom Sul. Anais... Chapecó-SC, Maio-Junho 2012.

ANDRADE, Zilda A. F. Gestão da ética nas organizações. São Paulo: ECA-USP, 2010 (Tese de doutorado em Comunicação)

ANDRADE, Zilda A. F. Relações Públicas: construindo relacionamentos éticos nas organizações. Texto apresentado no III Abrapcorp. Anais... São Paulo, Abril de 2009.

ARGENTI, Paul A. Comunicação empresarial - A construção da identidade, imagem e reputação. Rio de Janeiro: Elsevier, 2006.

BAUMAN, Zygmunt. A ética é possível num mundo de consumidores? Rio de Janeiro: Zahar, 2011.

BOYD, D.; ELLISON, N.B (2007). Social network sites: Definition, history, and scholarship. Journal of Computer-Mediated Communication, 13, 210-230.

BROUSTAU, Nadège.; FARMER, Yanick. Éthique et relations publiques: pratiques, tensions et perspectives. Communiquer, no. 11, Vol. 1, 2014, pp. 1-7.

DEGENNE, A.; e FORSÉ, M. Introducing Social Networks. London: Sage, 1999.

DUPAS, Gilberto. Ética e corporações: tensões entre interesse público e privado. Organicom, ano 5 , número $8,1^{\circ}$ sem. 2008 .

DUTTA-BERGMAN, Mohan J. Civil society and public relations: not so civil after all. Journal of Public Relations Research, Vol. 17, no. 3, 2005, pp. 267-289.

FAWKES, Johanna. Saints and sinners: competing identities in public relations ethics. Public Relations Review, No. 38, vol. 1, 2012, pp. 865-872.

GAGNÉ, A-M. La relation de confiance en relations publiques. Montreal: UQAM, 2012 (Tese de doutorado).

GOUVEIA, T. ; TAVARES, F. O imperativo das emoções positivas na comunicação das empresas na internet. Esferas, Ano 3, n⿳0 5, Julho-Dezembro de 2014, 115-125.

HUMBERG, Mario Ernesto. Ética organizacional e relações públicas. Organicom, ano 5, número $8,1^{\circ}$ semestre 2008 .

KUNSCH, Margarida Maria K. Gestão das relações públicas na contemporaneidade e sua institucionalização profissional e acadêmica no Brasil. Organicom, ano 3, no. 5, 20. semestre de 2006, pp. 31-61.

KUNSCH, Margarida Maria K. Planejamento de Relações Públicas na Comunicação Integrada. São Paulo: Summus, 2003.

KUNSCH, Margarida Maria Krohling. As dimensões humana, instrumental e estratégica da Comunicação Organizacional. Revista Intercom v.35, n.2, p. 267-289, jul./dez. 2012.

MACHADO, Jonas; BARICHELLO, Eugenia M. M. R. Comunicação de crise em mídias sociais digitais: um estudo do twittwe, do facebook e do blog corporativo da Petrobrás. Organicom, ano 12, no. 22, 1 semestre 2015, pp. 187-197. 


\section{VOZES $_{\text {\&IÁLORO }}^{\mid}$}

Itajaí, v. 18, n. 02, jul/dez 2019

MARQUES, A. C. S. O papel dos interesses na construção de uma ética dos processos comunicativos. Lumina, v. 5, p. 1-18, 2011.

MARTINO, Luís M. S. Rumo a uma teoria da midiatização. InTexto, no. 45, Vol. 1, maioagosto 2019, pp. 1-16.

MARTINO, Luís M. S.; MARQUES, Angela C. S. Ética, Mídia e Comunicação. São Paulo: Summus, 2018.

NASCIMENTO, Ana C. Chagas. A ética na atividade de relações públicas. Porto Alegre: PUC-RS, 2017 (Tese de doutorado em Comunicação).

PARSONS, T.; SHILL, E. A interação social. In: CARDOSO, F. H. e IANNI, O. (org.) Homem e Sociedade. (p.125-127) São Paulo: Companhia Editora Nacional, 1975.

PERES-NETO, L. Ética, comunicação em contextos organizacionais e defesa do consumo consciente. Animus, Vol. 12, no. 24, 2013, pp. 24-44.

PERES-NETO, Luiz. Ética, comunicação e organizações. Lumina, Vol. 8, no. 2, dezembro de 2014, pp. 1-18.

RECUERO, Raquel. Redes sociais na internet. Porto Alegre: Sulinas, 2009.

REGINATO, Gisele D.; POZZA, Débora Flores D. O discurso da responsabilidade social e da sustentabilidade na comunicação organizacional da Vale. Organicom, ano 10, no. 18, 2013, pp. 138-150.

RIVELLI, Fernanda Queiroz; MARTINO, L. M. S. A pesquisa em ética nas organizações: um estudo preliminar da produção acadêmica (2008-2018). Trabalho apresentado no XIII Abrapcorp. Anais... São Paulo: Faculdade Cásper Líbero, 2019.

ROSA, Fabio M.; CHEVITARESE, L. Vigilância e relações de poder nas redes sociais: questões éticas na sociedade contemporânea. Organicom, ano 14, no. 27, 20. semestre 2011, pp. 59-69.

SROUR, Robert Henry. Por que empresas eticamente orientadas? Organicom ano 5, número 8, $1^{\circ}$ semestre 2008 .

TASSIN, E. Espace commun ou espace public? L'antagonisme de la communauté et de la publicité. Hermès, 10, 1992, p.23-37.

VERHOEVEN, P. et a lli. Public relations and the rise of hypermodern values. Public Relations Review, n. 44, vol. 1, 2018, pp. 471-480.

WASSERMAN, S. e FAUST, K. Social Network Analysis. Methods and Applications. Cambridge: Cambridge University Press, 1994.

ZAMANI, Efpraxia; GIAGLIS, George M.; KASIMATI, Anna. Public relations crisis and social media. Journal of Theoretical and Applied Eletronic Commerce Research. VOl. 10, no. 2, Maio 2015, pp. 33-52. 